\title{
Monosodium Glutamate Induced Hepatotoxicity and Oxidative Stress: Pathophysiological, Biochemical and Electron Microscopic Study
}

\author{
HODA ATEF, M.D. ${ }^{\mathbf{1}}$; DOAA A. EL-MORSI, M.D. ${ }^{\mathbf{2}}$; MOHAMED EL-SHAFEY, M.D. ${ }^{\mathbf{3}, \mathbf{4}}$; \\ MOHAMED EL-SHERBINY, M.D. ${ }^{\mathbf{3}}$; HANY A. EL-KATTAWY, M.D. ${ }^{\mathbf{5 , 6}}$; ESLAM K. FAHMY, M.D. ${ }^{\mathbf{6}}$ and \\ ABEER ABD AL-MONIEM SAEED, M.D. ${ }^{6}$ \\ The Departments of Histology \& Cytology ${ }^{1}$, Forensic Medicine \& Clinical Toxicology ${ }^{2}$ and Anatomy ${ }^{3}$ \\ Faculty of Medicine, Mansoura University, Egypt, \\ Fakeeh College for Medical Sciences, Jeddah and Al-Maarefa College of Medicine, Riyadh ${ }^{5}$, Saudi Arabia and \\ The Department of Medical Physiology, Faculty of Medicine, Zagazig University, Zagazig, Egypt ${ }^{6}$
}

\begin{abstract}
Background: Monosodium Glutamate (MSG) is a widely used flavor enhancer with an umami taste.

Aim of the Work: The present work was designed to study the potential hepatotoxic effect of monosodium glutamate as regard biochemical; pathophysiological and electron microscopic changes; besides whether these changes were due to oxidative stress process. In addition, the possibility of recovery after MSG cessation was studied.
\end{abstract}

Material and Methods: The study was conducted on thirtysix adult male Sprague Dawley rats, classified into three groups (12/each). Distilled water was given orally to the control group for 90 days. Rats of MSG group administered daily oral dose of $4 \mathrm{mg} / \mathrm{Kg}$ for 90 days and the recovery group received the same dose as group II then kept four weeks later for recovery. After rats were sacrificed; blood samples were taken to measure liver enzymes [(Alanine Transaminase (ALT) and Aspartate Aminotransaminase (ASAT)], cholesterol and TGs. The liver tissues were used to measure products of oxidative stress and examined for histopathological; immmuohistochemical and Electron Microscopic (EM) changes.

Results: The results revealed statistically highly significant increase in hepatic enzymes, cholesterol, TGs and product of lipid peroxidation (Malondialdehyde, MDA) in combination with decrease in antioxidant glutathione transferase and superoxide dismutase in MSG group compared to control group $(p<0.001)$. The histopathological and immunohistochemical results showed steatosis; increased vacuolation; extensive fibrosis and apoptosis in the hepatic cells especially centrilobular in MSG group. EM confirms the previous changes.

Conclusion: It could be concluded that MSG has hepatotoxic and oxidant effects and its use should be prohibited during treatment of liver disorders.

Correspondence to: Dr. Hany A. El-Kattawy, E-Mail: hkataway@gmail.com
Key Words: $M S G$ - Oxidative stress - Hepatotoxicity - Hepatic enzymes - Rats.

\section{Introduction}

MONOSODIUM Glutamate (MSG), a salt of glutamic acid, is frequently used as a flavoring agent added to Chinese food, canned vegetables, soups and processed meats. Umami or meaty taste is largely elicited by glutamate [1]. Glutamate is naturally present in various foods including cheese, seafood, poultry and vegetables. However, added MSG is a common and powerful stimulus of umami taste in our human diets [2]. Glutamate receptors and transporters are expressed in the gastrointestinal tract. They include taste receptor 1, subtypes 1 and 3 (T1R1 and T1R3), metabotropic glutamate receptors (mGluRs), glutamate transporter-1 (GLT1), glutamateaspartate transporter-1 (GLAST-1) and excitatory amino acid carrier-1 (EAAC-1) [3] The National Agency for Food and Drug Administration Control expressed monosodium glutamate to be not harmful to health [4]. Despite there is no problem if MSG is consumed in small amounts in one food, yet daily consumption of different foods leads to health problem [5].

Oxidative stress is caused by the excessive production or a decreased elimination of free radicals in cells, the majority of which are oxygen radicals and other Reactive Oxygen Species (ROS). Therefore, excessive renal metabolism of glutamate as in chronic MSG intake can be a source of ROS [6]. However, the cellular antioxidant systems, including Superoxide Dismutase (SOD) and Glutathione S-Transferase (GST), are the main defense 
line against oxidative injury. Antioxidant system inhibition may cause accumulation of ${ }_{\mathrm{H} 2 \mathrm{O} 2}$ or decomposition products [7]. As the glutamate is metabolized mainly in the liver, so exposure to large doses may produce histological changes [8]

Several experimental studies had shown that MSG was toxic to various organs such as the CNS, liver, kidneys, endometrium; thyroid, spleen and thymus; testes and had genotoxic effect [9-17].

The current work aimed to investigate the hepatotoxic effect of monosodium glutamate as regard biochemical; pathophysiological and electron microscopic changes; besides whether these changes were due to oxidative stress process. In addition to, study the possibility of recovery after MSG cessation.

\section{Material and Methods}

The study was performed in the period from 10th January to 21 th June 2017 at Faculty of Medicine, Mansoura University.

\section{Chemicals:}

Monosodium Glutamate (MSG) (C5H9NO4$\mathrm{Na}$ ) was purchased from Al-Dawlya Chemicals Co., Egypt with Purity $>98 \%$ NT. Stock solution was prepared by dissolving $10 \mathrm{~g}$ of MSG crystals in $100 \mathrm{ml}$ of distilled water $1 \% \mathrm{w} / \mathrm{v}$ MSG $(60 \mathrm{mM}$ in water) [18]

\section{Animals and study design:}

Thirty six Sprague Dawley adult male rats (8 weeks, weighting 200-250g) were purchased from the Animal House of Medical Experimental Research Center (MERC); Faculty of Medicine, Mansoura University, animals housed within soft wooden cages, under standard temperature $\left(25-30^{\circ} \mathrm{C}\right)$ with 12-h light/dark cycle (seven rats per cage). The rats received standard laboratory chow (Purina) and water ad libitum. The experimental protocol met the ethical guidelines and the principles of care, use, and handling of animals adopted by the Research Ethical Committee, Faculty of Medicine, Mansoura University, Egypt which conform to the international guidelines set by National Institutes of Health guide for the care and use of Laboratory animals. Rats were classified into three groups (12/group):

Group I (Control group): Four $\mathrm{mL}$ distilled water was given orally daily for 90 days.

Group II (Monosodium Glutamate, MSG group): Four $\mathrm{mg} / \mathrm{Kg}$ MSG was given daily by oral gavage for 90 days.
Group III (recovery group): Rats received the same dose as group II then kept four weeks later for recovery [12].

\section{Sampling:}

With termination of the study (90 days), rats were anesthetized by thiopental sodium $(40 \mathrm{mg} / \mathrm{kg})$, sacrificed by decapitation and blood samples were collected by cardiac puncture in dry tubes without anticoagulant to measure liver enzymes [(Alanine Transaminase (ALT) and Aspartate Amino Transaminase (ASAT)]. The liver tissues were excised and prepared to measure the products of oxidative stress and examined for histopathological; immmuohistochemical and electron microscopic changes.

\section{Methods:}

- Liver enzymes assay: The blood samples were left to clot and then centrifuged at 3000rpm for $10 \mathrm{~min}$. Sera were stored at $-20^{\circ} \mathrm{C}$ till analysis according to Reitman and Frankel [19]

- Blood lipids assay: Assessments of serum levels of cholesterol and TGs were done using supplies from SPINREACT (Ctra. Santa Coloma, SPAIN) following company's procedures.

- Measurement of oxidative stress markers in liver homogenate: Liver tissues were processed to make $10 \%(\mathrm{w} / \mathrm{v})$ homogenate in ice-cold $20 \mathrm{mM}$ tris (hydroxymethyl) aminomethane buffer ( $\mathrm{pH}$ 7.4). Homogenates were centrifuged at $3000 \mathrm{X}$ $\mathrm{g}$ for $30 \mathrm{~min}$ at $4^{\circ} \mathrm{C}$. The supernatant were collected and assayed for Malondialdehyde (MDA), Superoxide Dismutase (SOD) and Glutathione STransferase (GST).

Hepatic Malondialdhyde (MDA), as an indicator of lipid peroxidation was estimated as MDA and determined according to Varshney and Kale [20], using Biodiagnostic Kit.

Hepatic Superoxide Dismutase (SOD), was determined using the Phenazine-Metho-Sulfate (PMS) method, which depends on the ability of SOD to inhibit the PMS mediated reaction of Nitroblue Tetrazolium (NBT) according to Misra and Fridovich [21]

Glutathione S-Transferase (GST), activity was assayed according to the method of Rajukar et al., [22] using 1-chloro-2, 4-dinitrochlorobenzene (CD$\mathrm{NB}$ ) as substrate. The GST unit is defined as $1 \mathrm{~mol}$ of CDNB-GSH conjugate formed $/ \mathrm{min} / \mathrm{mg}$ protein.

Histopathological and Immunohistochemical study of liver tissues: For immunohistological, fixation of liver sections was done with $15 \%$ phos- 
phate buffered formalin solution and embedded in paraffin. Five micrometer-thickness sections were deparaffinized with xylene by specialized technician. Two different sections, at least; were examined per liver sample in random order. A total of three sets of slides were prepared for the following histopathological and immunohistochemical evaluation.

Hematoxylin and Eosin $(H \& E)$ stain: First set of the slide was stained with $\mathrm{H} \& \mathrm{E}$ for evaluating histopathological changes [23]. Ishak Modified HAI [24] (1).

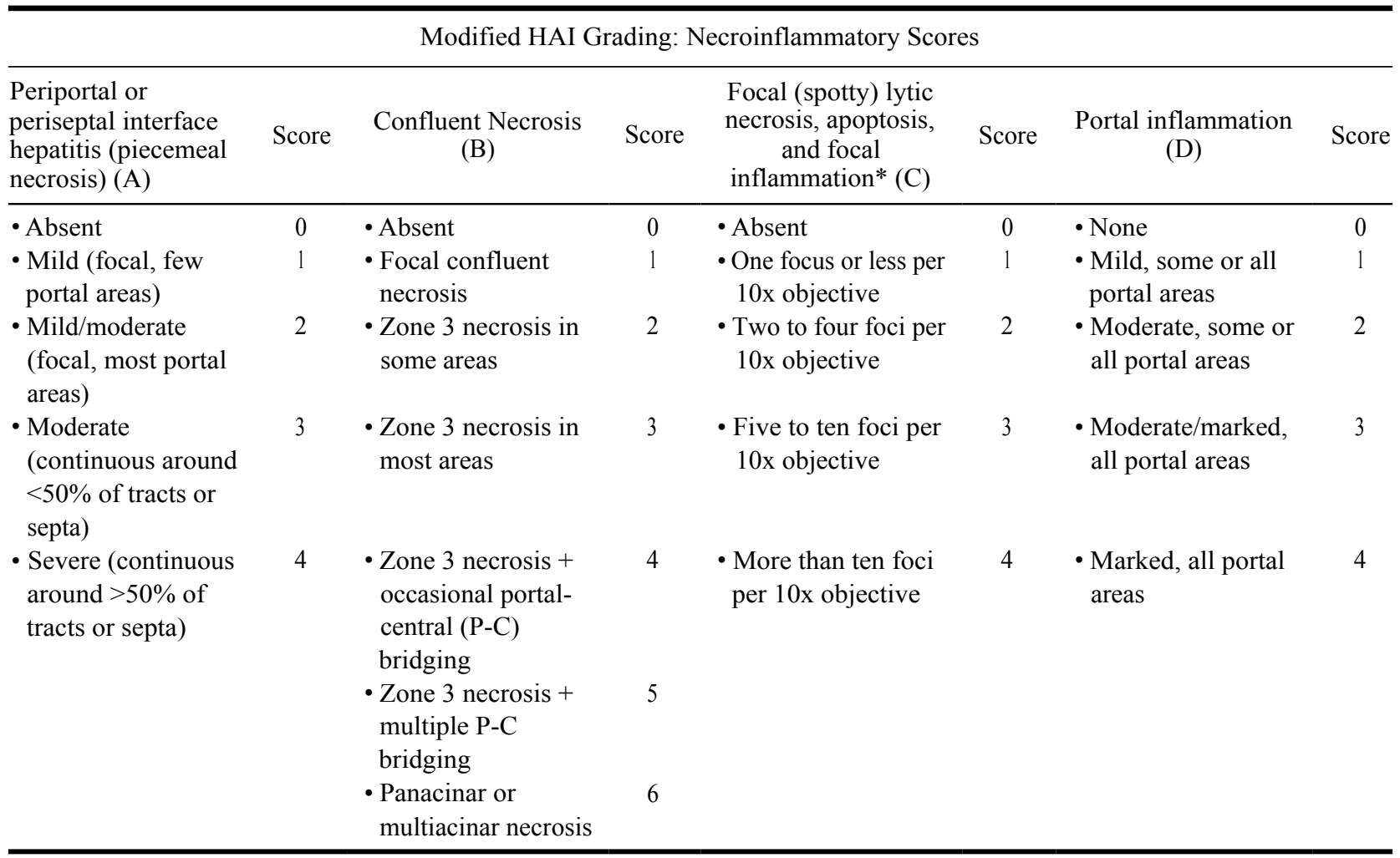

*: Does not include diffuse sinusoidal infiltration by inflammatory cells.

Masson's Trichome stain: Collagen and the other Extracellular Matrix components (ECM) were evaluated in the second set of slides by Masson's Trichome stain. Areas of fibrosis stained blue while the parenchyma stained red and assessed by modified Ishak's staging system [24].

Modified Ishak staging system "Histological Activity Index (HAI)" staging:

\begin{tabular}{lc}
\hline Change & Score \\
\hline - No fibrosis & 0 \\
- Fibrous expansion of some portal areas, with or & 1 \\
& without short fibrous septa \\
- Fibrous expansion of most portal areas, with or & 2 \\
& without short fibrous septa \\
- Fibrous expansion of most portal areas with & 3 \\
occasional portal-portal (P-P) bridging & \\
- Fibrous expansion of portal areas with marked & 4 \\
bridging (portal-portal (P-P) as well as portal-central & \\
(P-C) & $\begin{array}{l}\text { Marked bridging (P-P and/or P-C) with occasional } \\
\text { nodules (incomplete cirrhosis) }\end{array}$ \\
- Cirrhosis, probable or definite & 5 \\
\hline
\end{tabular}

Immunohistochemical staining for cleaved caspase-3: The third set of slides was stained with rabbit anti-cleaved Caspase-3 for detecting the areas of apoptosis. Before immunohistochemical staining, the liver sections were subjected to heatinduced epitope retrieval by incubation in a 0.01 $\mathrm{M}$ sodium citrate solution $(\mathrm{pH} 6)$ at $12^{\circ} \mathrm{C}$ for $10 \mathrm{~min}$, followed by a two hr. cool-down. Primary antibodies were diluted in the following buffer: $0.1 \mathrm{M}$ PBS, $0.3 \%(\mathrm{~m} / \mathrm{v})$ BSA, $0.1 \%(\mathrm{~m} / \mathrm{v})$ sodium azide, $0.06 \%(\mathrm{~m} / \mathrm{v})$ n-ethyl-maleimide, and $20 \%(\mathrm{v} / \mathrm{v})$ glycerol.

Active caspase- 3 was detected with a speciesunspecific rabbit polyclonal antibody $(1: 1000$ diluted; BD Biosciences, Le Pont-de-Claix, France) that specifically recognize the large fragment (17 $\mathrm{KDa}$ ) of the active protein but not full-length caspase-3. Antibodies were applied for $16 \mathrm{hr}$ at $4^{\circ} \mathrm{C}$. The deparaffinized sections were rinsed in phosphate buffered saline and endogenous peroxidase activity was blocked by incubation with $3 \%$ 
hydrogen peroxide for 10 minutes at room temperature.

The sections were washed with phosphate buffer saline tween (0.1 M phosphate buffer, $\mathrm{pH} 7.4,0.1 \%$ (v/v) Tween 20) over 10min and incubated with biotinylated goat anti-rabbit antibody (Dakocytomation; Trappes, France) diluted 1:200 for $1 \mathrm{hr}$ at room temperature. The reaction was visualized by using 3, 3'-diaminobenzidine. Liver sections were stained with hematoxylin, dehydrated in ethanol and cleared with xylene [25].

Then the slides were photographed using Olympus $®$ digital camera installed on Olympus $®$ microscope with $1 / 2 \mathrm{X}$ photo adaptor, using 400 $\mathrm{X}$ objective. The result images were analyzed on Intel ${ }^{\circledR}$ Core I3® based computer using VideoTest Morphology® software (Russia) with a specific built-in routine for area, \% area measurement and object counting.

Transmission electron microscopy: The fixed pieces of liver tissues were rinsed in cacodylate buffer $0.1 \mathrm{M}$, and $1 \%$ osmium tetroxide for post fixation for one hour. Ethanol gradient series used for dehydration and specimens were embedded in Epon. Ultra-thin sections were cut at thickness of $80 \mathrm{~nm}$, mounted on copper grids and stained with uranyl acetate $5 \%$ for $15 \mathrm{~min}$ followed by lead citrate for $8 \mathrm{~min}$ and examined by transmission electron microscope; (JEOL, JEM-2100, Electron Microscopic Unit, Mansoura University) [26].

\section{Statistical analysis:}

Data were collected and analyzed using the Statistical Package for Social Sciences (SPSS) Version 16. Qualitative data were described as numbers and percentages. Quantitative data were described as means \pm SD or median, as appropriate. They were tested for normality by KolmogorovSmirnov test. In the normally distributed variables, one way ANOVA test was used for comparison between groups with postHOC LSD (least significant difference). While in non-normally distributed variables, Kruskal-Wallis test and Mann-Whitney test were used for comparison between groups. $p$ value $\leq 0.05$ was considered to be statistically significant.

\section{Results}

Biochemical assay demonstrated the changes in liver enzymes, blood lipid levels and products of oxidative stress. MSG group exhibited high statistically significant increase in liver enzymes, cholesterol, TGs and MDA with high statistically significant reduction in antioxidant enzymes; GST and SOD; compared to the control group $(p<0.001)$. While in the recovery group, there are reduction in the liver enzymes and lipid peroxidation with increase in antioxidant enzymes; GST and SOD (Table 1).

Table (1): Changes in liver enzymes; oxidative stress products and apoptosis in all studied groups.

\begin{tabular}{|c|c|c|c|c|}
\hline Parameters & $\begin{array}{l}\text { Control group } \\
n=12\end{array}$ & $\begin{array}{c}\text { MSG group } \\
n=12\end{array}$ & $\begin{array}{l}\text { Recovery group } \\
\mathrm{n}=12\end{array}$ & $\begin{array}{c}\text { Test of } \\
\text { significance }\end{array}$ \\
\hline ALT & $18.92 \pm 0.17 \mathbf{a b}$ & $40.67 \pm 4.7 \mathbf{a}$ & $35.7 \pm 7.4^{\mathbf{b}}$ & $\begin{array}{l}\mathrm{F}=67.8 \\
p<0.001 * *\end{array}$ \\
\hline ASAT & $86.83 \pm 0.7^{\mathbf{c d}}$ & $156.0 \pm 13.7^{\mathrm{c}}$ & $121.0 \pm 20.8 \mathbf{d}$ & $\begin{array}{l}\mathrm{F}=77.6 \\
p<0.001 * *\end{array}$ \\
\hline Cholesterol & $90 \pm 0.25 \mathbf{a b}$ & $105 \pm 0.1^{\mathrm{a}}$ & $91.2 \pm 21 \mathbf{b}$ & $\begin{array}{l}\mathrm{F}=70.6 \\
p<0.001 * *\end{array}$ \\
\hline TGs & $77 \pm 0.23^{\mathbf{a b}}$ & $80 \pm 0.26 \mathbf{a}$ & $67.5 \pm 0.21 \mathbf{b}$ & $\begin{array}{l}\mathrm{F}=80.2 \\
p<0.001 * *\end{array}$ \\
\hline MDA & $1.26 \pm 0.02 \mathbf{e f}$ & $3.34 \pm 0.37^{\mathrm{e}}$ & $2.2 \pm 0.2 \mathbf{f}$ & $\begin{array}{l}\mathrm{F}=220.1 \\
p<0.001 * *\end{array}$ \\
\hline GST & $2.14 \pm 0.02 \mathbf{x y}$ & $0.95 \pm 0.08^{\mathbf{x}}$ & $1.2 \pm 0.25 \mathbf{y}$ & $\begin{array}{l}\mathrm{F}=238.8 \\
p<0.001 * *\end{array}$ \\
\hline SOD & $25.8 \pm 0.07$ gh & $14.5 \pm 2.3 \mathrm{~g}$ & $17.63 \pm 2.74^{\mathbf{h}}$ & $\begin{array}{l}\mathrm{F}=102.3 \\
p<0.001 * *\end{array}$ \\
\hline Apoptosis area $(\mathrm{m})$ & $\begin{array}{l}22450.0^{\mathbf{a b}} \\
(20563.0-68318.0)\end{array}$ & $\begin{array}{l}235493.0^{\mathbf{a}} \\
(185263.0-312043.0)\end{array}$ & $\begin{array}{l}99421.0^{\mathbf{b}} \\
(88457.0-157423.0)\end{array}$ & $\begin{array}{l}\mathrm{KW} \chi^{2}=28.4 \\
p<0.001 * *\end{array}$ \\
\hline $\begin{array}{l}\text { All parameters described a } \\
\text { ALT : Alanine Transamin } \\
\text { m : Micrometer. } \\
\text { ASAT : Aspartate Aminotr } \\
\text { MDA : Malondialdehyde. } \\
\text { GST : Glutathione S-Trar } \\
\text { SOD : Superoxide Dismu }\end{array}$ & $\begin{array}{l}\text { mean } \pm \text { SD except ap } \\
\text { se. } \\
\text { isaminase. } \\
\text { ferase. } \\
\text { se. }\end{array}$ & $\begin{array}{cl}\text { is as median (min-max). } \\
\text { MSG } & : \text { Monosodium } \\
\text { SD } & : \text { Standard Dev } \\
\text { F } & : \text { One way ANC } \\
\text { KW } \chi^{2} & : \text { Kruskal Walli } \\
* * & : \text { High statistic } \\
\text { a,b,c,d } & \text { Similar letter }\end{array}$ & $\begin{array}{l}\text { tamate. } \\
\text { n. } \\
\text { test. } \\
\text { t. } \\
\text { significant. } \\
\text { ote significant differenc }\end{array}$ & tween groups. \\
\hline
\end{tabular}




\section{- Histopathological results:}

$A-H \& E$ stain: In the control group the hepatocytes has normal architecture. With no signs of necro-inflammatory changes. In MSG group; most of the hepatocytes were vacuolated with steatosis with necro-inflammatory changes (score 3 in modified HAI grading scores). Furthermore, in the recovery group, the liver showed significant improvement, nearly normal hepatic architecture, and necro-inflammatory score 1 in modified HAI grading for scores Fig. (1).

B- Masson Trichrome stain: In the control group, the connective tissue appeared minimal between the hepatic lobules around the central veins and in the wall of the sinusoids; while the MSG group, there were extensive fibrosis (stage 4 fibrosis according to modified Ishak staging system); moreover in the recovery group, there was mild perivenular, periportal fibrosis and stage 1 fibrosis Fig. (2).
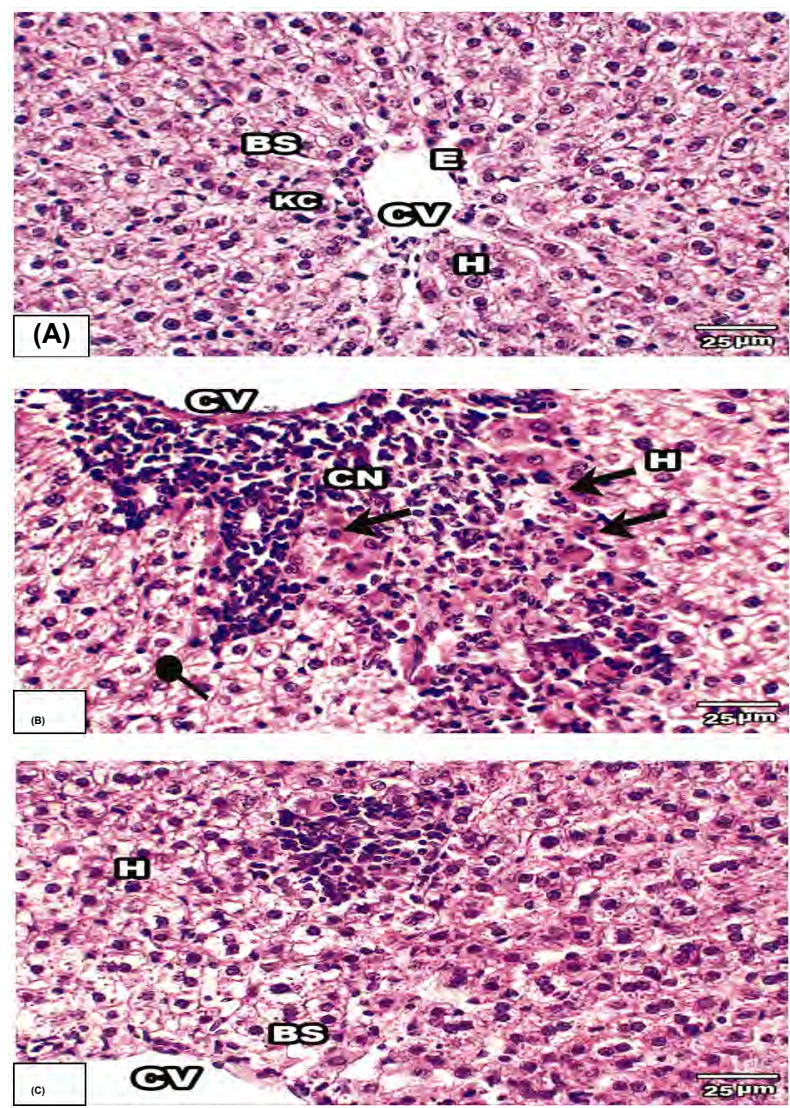

Fig. (1): Photomicrograph of liver tissues stained with hematoxylin and eosin showing (A) Control group with normal hepatic architecture without necro-inflammatory changes, (B) MSG group reveal ballooning (oval arrow), fatty degeneration of hepatocytes, focal lytic necrotic lesions, apoptotic bodies (arrows), marked increase in hepatocellular regenerative activity by formation of cholangioles and necroinflammatory score 3 in modified HAI grading scores, (C) Recovery group reveal significant hepatic improvement, the hepatic architecture is more or less intact, few focal hepatocyte regenerations and necroinflammatory score 1 in modified HAI grading for scores $(\mathrm{CV}$ : Central Vein, BS: Blood Sinusoids; H: Hepatocytes; KC: Kupffer Cells; E: Endothelial lining; CN: Condensed Nuclei) (400X).
- Immunohistochemical stain: The apoptosis area and \% in each group showed in (Table 1) with high statistically significant differences between groups $(p<0.001)$. In addition, in the control group, hepatic sections were negative for caspase 3 ; while in MSG group, there was caspase 3 positive reaction in multiple areas of hepatic tissues; furthermore, the apoptosis was markedly decreased in the recovery group (the image analysis revealed that the of apoptotic area was 22450 in control group, 235493 in MSG group and 99421 in recovery group) Fig. (3).

- $E / M$ : In sections examined with TEM in control group, normal hepatic structures were prominent; in MSG group, hepatocytes cytoplasm with irregular nuclei, increased lipid droplets and numerous swollen mitochondria were observed with multiple erythrocytes were seen in sinusoid. While in the recovery group the microvilli in the space of Disse and mitochondria with its elongated shape and few lipid droplets were restored Figs. (4-6).
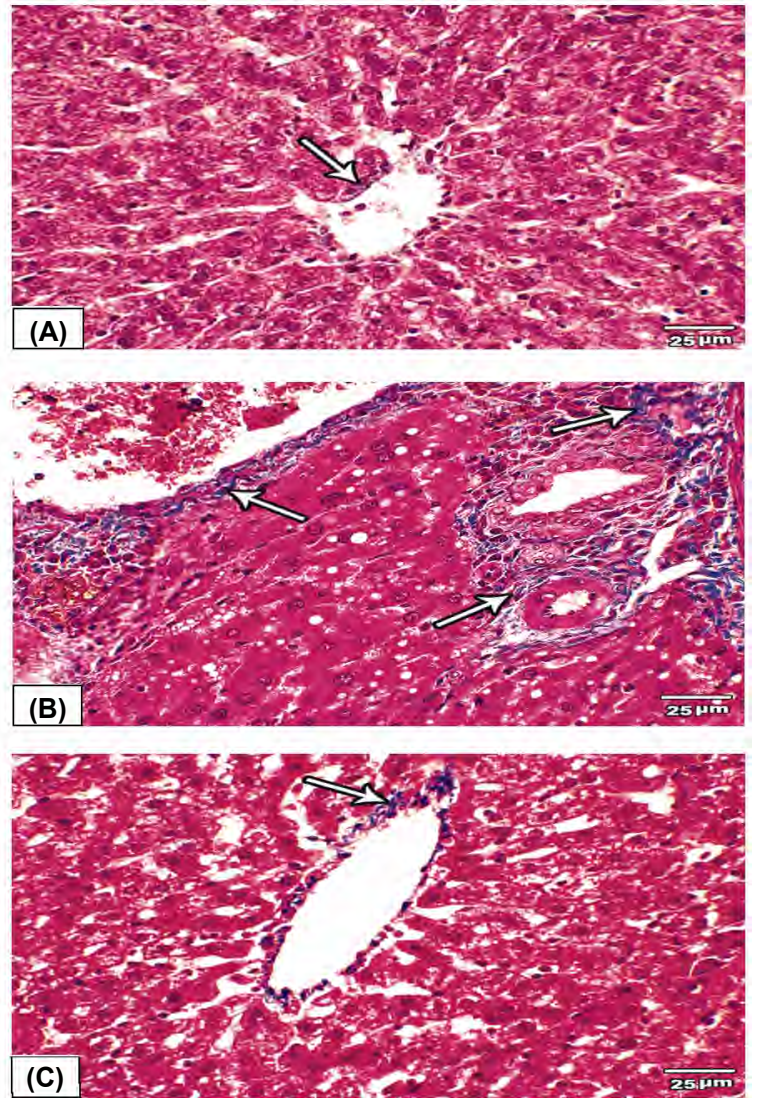

Fig. (2): Photomicrograph of liver tissues stained with Masson's Trichrome showing (A) Control group with no fibrosis, (B) MSG group with stage 4 fibrosis according to modified Ishak staging system, (C) Recovery group with mild perivenular, periportal fibrosis and stage 1 fibrosis according to modified Ishak staging system (400X). 

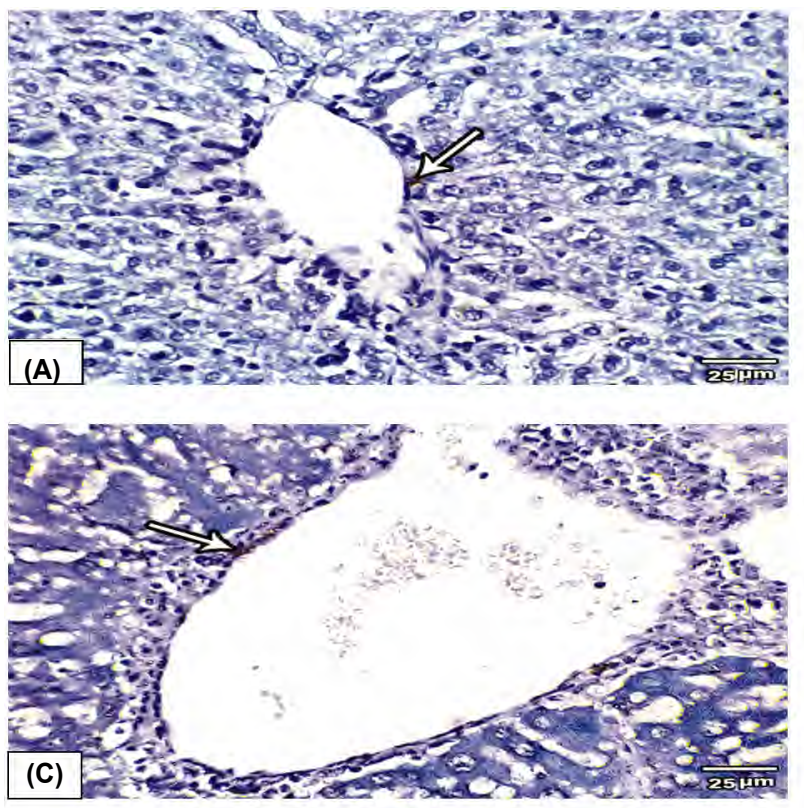

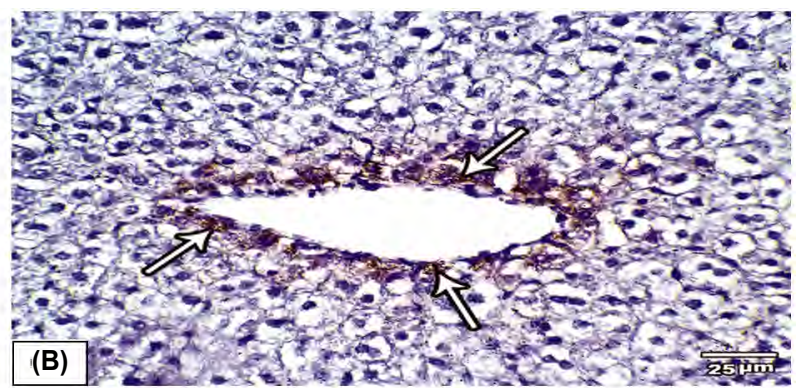

Fig. (3): Photomicrograph of liver tissue stained with anti-caspase 3 immunostain reveal (A) Control group with negative expression of caspase-3, (B) MSG group with extensive caspase-3 immunolabeled hepatocytes expression but markedly decreased in the recovery group (C) $(400 X)$.
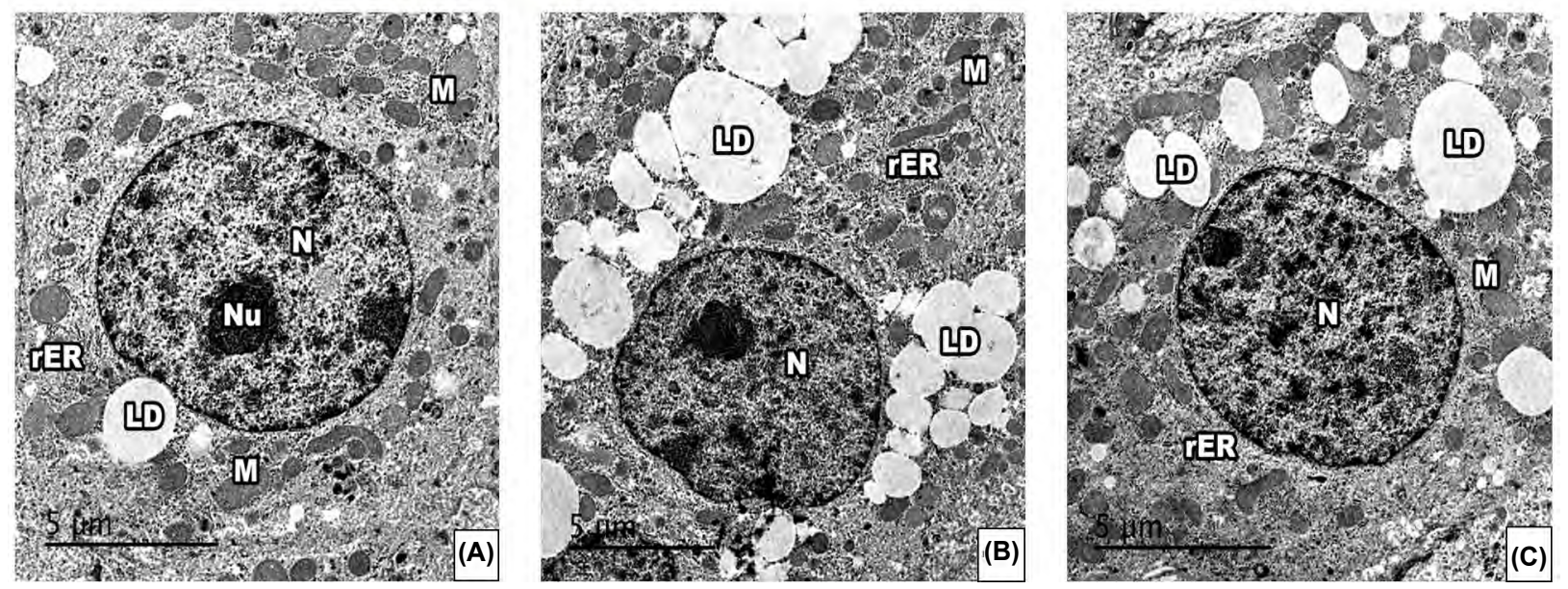

Fig. (4): Electron Micrographs of liver tissues reveal (A) Control group with normal hepatocyte and few lipid droplets, (B) MSG group with increased lipid droplets in the hepatocytes which decreased in the recovery group (C) (N: Euchraomatic nucleus; Nu: Nucleolus; M: Mitochondria; rER: Rough endolasmic reticulum; LD: Lipid Droplet).
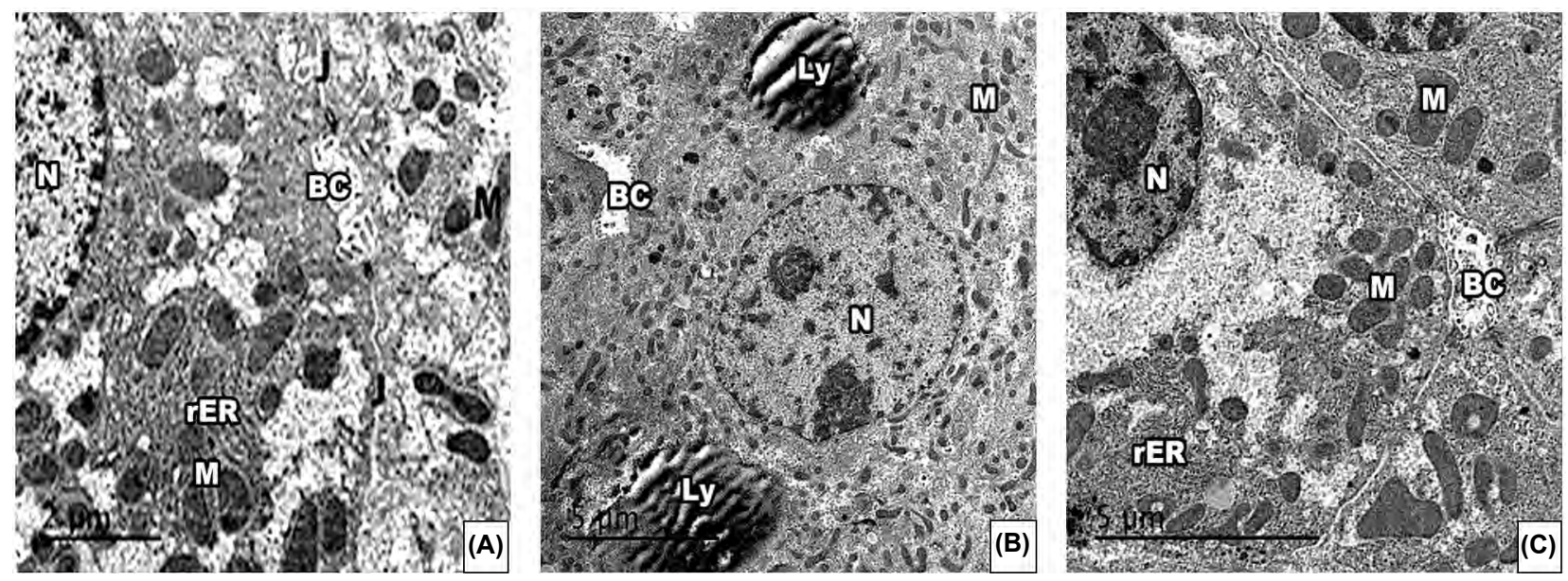

Fig. (5): Electron Micrographs of liver tissues showing (A) Control group with normal hepatocytes cytoplasm and abundant rough endoplasmic reticulum with elongated mitochondria. Abundant microvilli of hepatocytes were noted in the lumen of the bile canaliculus with junctional complex, (B) MSG group showing hepatocytes cytoplasm with large abnormal lipid droplets. Microvilli of hepatocytes were disrupted in the lumen of the bile canaliculus with no abundant junctional complex, (C) Recovery group showing hepatocyte with small abnormal lipid droplet and restored microvilli of hepatocytes in the lumen of the bile canaliculus (N: Nucleus, M: Mitochondria, rER: Rough endoplasmic reticulum, Ly: Lysosome; BC: Blood sinusoids). 

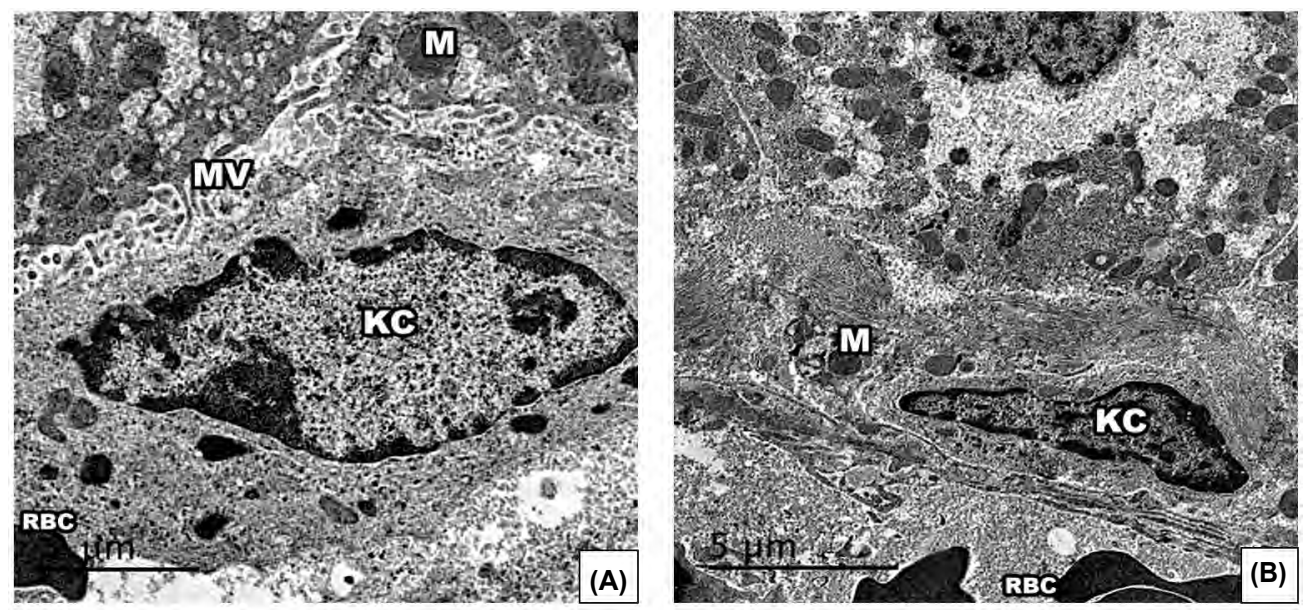

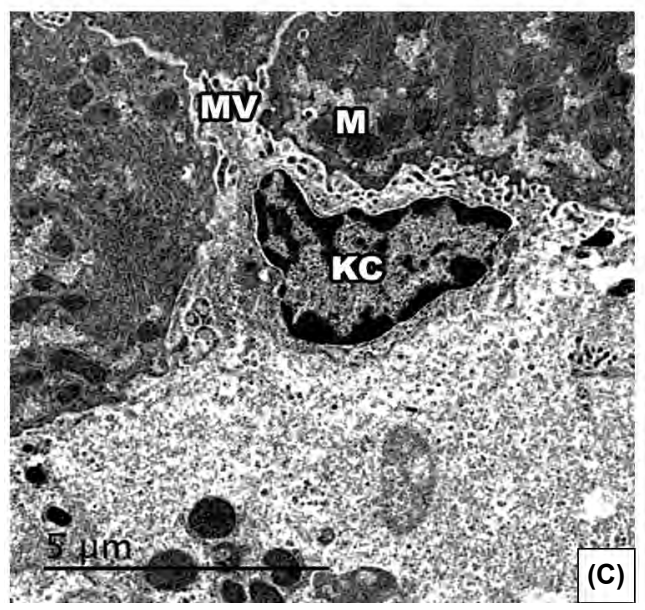

Discussion

Monosodium Glutamate (MSG) is a commonly used as a food additive worldwide. The present work aimed to investigate the hepatotoxic effect of monosodium glutamate as regard biochemical; pathophysiological; and electron microscopic changes; besides whether these changes were due to oxidative stress process. In addition to, study the possibility of hepatic recovery after MSG cessation.

The current results revealed high statistically significant impairment of liver function as indicated by significant increase in ALT and ASAT enzymes in MSG group. This is in agreement to Kumar et al., [8] who found a significant increase in the alanine aminotransferase and aspartate aminotransferase in the MSG group compared to the control group. The same findings were reported by Ortiz et al., [27] ; Inuwa et al., [28]; Kolawole [29]. The transaminases are cytoplasmic in location and plentiful in the liver. Plasma levels of transaminases are free into the flowing blood only after structural damage and were used as an indicator of mechanical damage to the liver [30].
Fig. (6): Electron micrographs of liver tissues showing (A) Control group with normal hepatocytes and microvilli extended into the space of Disse which is lined by sinusoidal endothelium. Erythrocyte was noted in the sinusoid, (B) MSG group showing hepatocytes cytoplasm with swollen mitochondria and fibrillary deposition. Altered space of Disse was seen with no hepatocytes microvilli extending in it. Changes in endothelial cell shape were noted compared to normal. Multiple eryrhtrocytes were seen in sinusoid, (C) Recovery group showing hepatocyte with restored microvilli in the space of Disse. (M: Mitochondria, MV: hepatocyte microvilli, KC: Von Kupffer cell; RBC: Red Blood Corpuscle).

As regard oxidative stress parameters; the MSG group had a high statistically significant difference from the control group. This is similar to the study done in 2006, by Ortiz et al., [27] who reported an increase in MDA as a response to liver damage. In addition, Egbuonu et al., [31] mentioned that the level of lipid peroxidation (MDA) was increased in MSG group. Also, Ashry et al., [32] and Diab and Hamza in [33] observed an increase in MDA and decrease in the antioxidant enzymes (GST and SOD) in MSG group.

The increase in lipid peroxidation may be attributed to a direct effect of increased generation of ROS and an attempt by the tissues to restore their normal oxidative state. Also, the decrease in the activities of GST and SOD could result from their inactivation by ROS or by their glycation [33]. Glutathione acts as a direct radical scavenger and may stabilize membrane structure by removal of free radicles formed during lipid peroxidation reaction. So reduction of glutathione is a good sign of tissue degeneration and the degree of depletion is related to the severity of damage. Furthermore, the decrease in SOD might be contributed to the increase in the lipid peroxidation [11]. 
We detected a major increase in total plasma cholesterol go together with increase TGs in monosodium glutamate treated rats and suggested a change in glucose metabolism towards lipogenesis which explain the hyperlipidaemia. Monosodium glutamate probably was able to increase the actions of 3-hydroxyl-3-methylglutaryl coenzyme A (HMG $\mathrm{CoA}$ ) reductase; the regulating enzyme in the synthesis of cholesterol causing increase the cholesterol synthesis in the MSG treated rats [34].

Furthermore; the histopathological; immunohistochemical and EM studies revealed steatosis; increased vacuolation; increased lipid droplets; abundant rough endoplasmic reticulum and swollen mitochondria; extensive fibrosis and apoptosis in the hepatic cells specially centrilobular in MSG group which return to about normal in the recovery group as the liver enzymes and lipid peroxidation were decreased with increased antioxidant enzymes. Also the hepatic architecture was nearly normal and the necro-inflammatory score was improved from stage 3 to stage 1, the fibrosis improved from stage 4 to stage 1 and the percentage of apoptotic area was significantly decreased to $0.09 \%$.

The present results are consistent with studies of Eweka and Om'Iniabohs [35] and Bhattacharya et al., [36] who used $\mathrm{H}$ \& E stain to study the hepatotoxic effects of MSG. As the centrilobular hepatocytes have more surface receptors, so they are the primary sites of toxins. As a defense mechanism against toxic substance, the hepatocytes tend to vacuolate. These vacuoles are responsible for prevention of the toxic substance from interfering with the biological activities of these cells [8].

In addition, Egbuonu et al., [37] sated that the circulating MSG is dissociated and glutamate is released. Glutamate is excitatory amino acid with excitotoxin effect through its deamination and production of ammonium ions that are toxic unless detoxified in the liver. These changes in hepatic cells could be explained by the oxidative stress effect of MSG and ROS generation which activates mitochondrial porous leakage with discharge of different apoptogenic factors like procaspase, cytochrome $\mathrm{c}$, apoptosis inducing factor and apoptosis protease-activating factor 1 , into the cytosol, that induce activation of caspases.

In this study, oxidative stress biomarkers (MDA) and antioxidant enzymes (GST and SOD) were assessed in in rat liver as, these markers of oxidative stress are sensitive to cellular membrane damage, which can lead to damage of hepatic architecture and occurrence of programmed cell death (apopto- sis) [34]. Most of these changes including fibrosis and inflammation in this study as a result of ROS were attenuated by the liver after withdraw MSG by increase the antioxidants such as (GST) and (SOD) which was detected by biochemical markers and immunohistolochemical analysis.

\section{Conclusion:}

It could be concluded that MSG has hepatotoxic and oxidant effects and its use should be prohibited during treatment of liver disorders and during the prevention or treatment of oxidative stress. These changes have public and clinical implications, so the individuals and food agencies should restrict the dietary intake of MSG as a food flavor. Also the cessation of MSG lead to improvement of the biochemical and pathological changes but did not return to normal.

\section{References}

1- JINAP S. and HAJEB P.: Glutamate: Its applications in food and contribution to health. Appetite, 55 (1): 1-10, 2010.

2- GHIRRI A. and BIGNETTI E.: Occurrence and role of umami molecules in foods. Int. J. Food Sci. Nutr., 63 (7): 871-81,2012.

3- ZHANG J., YIN Y., GANG X.S., LI T., LI F., TAN B., WU Z. and WU G.: "Oral administration of MSG increases expression of glutamate receptors and transporters in the gastrointestinal tract of young piglets" Amino Acids, 45: 1169-1177 Doi 10.1007/s00726-013-1573-2, 2013.

4- GANESAN K., SUKALINGAM K., BALAMURALI K., et al.: "A study on monosodium L-glutamate toxicity in animal model: A review". Int. J. Pharamaceutical, Chemical and Biological Science, 3 (4): 1257-68, 2013.

5- SINGH K., SHARMA J., KAUR A. and AHLUWALIA P.: "Alteration upon oral ingestion of monosodium glutamate in various lipid and lipoprotein fractions in serum of adult male rat". J. Life Sci., 3 (1): 17-21, 2011.

6- PAUL M.V., ABHILASH M., VARGHESE M.V., ALEX M. and NAIR R.H.: "Protective effects of alpha-tocopherol against oxidative stress related to nephrotoxicity by monosodium glutamate in rats". Toxicol. Mech. Methods, 22 (8): 625-30, 2012.

7- AL-HARBI M.S., EL-SHENAWY N.S. and AL-WEAIL N.O.S.: "Effect of monosodium glutamate on oxidative damage in the male mice: Modulatory role of vitamin C". Adv. Food Sci., 36 (4): 167-76, 2014.

8- KUMAR S., KUMAR N. and KUMAR B.: "Evaluation of monosodium glutamate induced hepatotoxicity in adult wistar albino rats". World J. Pharmaceutical Research, 4 (2): 569-84, 2015.

9- ABASS M.A. and ABD EL-HALEEM M.R.: "Evaluation of monosodium glutamate induced neurotoxicity and nephrotoxicity in adult male albino rats". J. American Sci., 7 (8): 264-76, 2011.

10- BHATTACHARYA T., BHAKTA A. and GHOSH S.K. "Long term effect of monosodium glutamate in liver of 
albino mice after neo-natal exposure". Nepal Medical College J., 13 (1): 11-6, 2011.

11- OKWUDIRI O.O., SYLVANUS A.C. and PEACE I.A.: "Monosodium glutamate induces oxidative stress and affects glucose metabolism in the kidneys of rats". Int. J. Biochemistry Research \& Review, 2 (1): 1-11, 2012.

12-HASSAN Z.A., ARAFA, M.H., SOLIMAN W.I., ATTEIA H.H. and AL-SAEED H.F.: "The effects of monosodium glutamate on thymic and splenic immune functions and role of recovery (biochemical and histological study)". Cytology and Histology, 5 (6): 1-9, 2014.

13- WAHYUNI E.D., SITUMORANG C.C., YUENIWATI Y., et al.: "Combination of vitamin $\mathrm{C}$ and $\mathrm{E}$ modulated monosodium glutamate induced endometrial toxicity in female wistar rats". Asian Pacific J. Reproduction, 3 (2): 106-9, 2014.

14- KHALAF H.A. and ARAFAT E.A.: "Effect of different doses of monosodium glutamate on the thyroid follicular cells of adult male albino rats: A histological study". Int. J. Clin. Exp. Pathol., 8 (12): 15498-510, 2015.

15-ABD-ELLA E.M. and MOHAMMED A.M.: "Attenuation of monosodium glutamate-induced hepatic and testicular toxicity in albino rats by Annona Muricata Linn. (Annonaceae) leaf extract". J. Pharmacy and Biological Sciences, 11 (6): 61-9, 2016.

16- ATASEVEN N., YUZBASIOGLU D., KESIN A.C. and UNAL F.: "Genotoxicity of monosodium glutamate". Food and Chemical Toxicology, 91: 8-18, 2016.

17- ROSA S.G., CHAGAS P.M., PESARICO A.P. and NOGUEIRA C.W.: "Monosodium glutamate induced nociception and oxidative stress dependent on time of administration, age of rats and susceptibility of spinal cord and brain regions". Toxicol Appl Pharmacol., 15; 351: 64-73. doi: 10.1016/j.taap.2018.05.019. Epub, 2018.

18- KONDOH T. and TORII K.: "MSG intake suppresses weight gain, fat deposition, and plasma leptin levels in male Sprague-Dawley rats". Physiol. Behav., 95: 135-44, 2008.

19- RITMAN S. and FRANKEL S.: "A colorimetric method for the determination of serum glutamic oxaloacetic acid and glutamic pyruvic transaminase”. Am. J. Clin. Pathol., 28: 56-63, 1957.

20- VARSHNEY R. and KALE R.K.: "Effects of calmodulin antagonists on radiation induced lipid peroxidation in microsomes”. Int. J. Rad. Biol., 58: 733-43, 1990.

21- MISRA H. and FRIDOVICH I.: "The role of superoxide anion in the autooxidation of epinephrine and simple assay for superoxide dismutase". J. Biol. Chem., 247: 3170, 1972.

22- RAJURKAR R.B., KHAN L.H. and GIJAR G.T.: "Studies on levels of glutathione s transferase, its isolation and purification from Helicoverpa amigera". Current Science, 85 (9): 1355-60, 2003.

23- BANCROFT J.D. and GAMBLE M.: Theory and Practice of Histopathological Technique; 6 th ed., 601-15, 2008.

24- ISHAK K., BAPTISTA A., BIANCHI L., et al.: "Histologic grading and staging of chronic hepatitis". J. Hepatol., 24: 289-93, 1995.

25- MARCHAL S., FRANCOIS A., DUMAS D., GUILLEMIN F. and BEZDETNAYA L.: "Relationship between subcellular localization of Foscan and caspase activation in photosensitized MCF-7 cells". Br. J. Cancer, 96: 94451, 2007.

26- GLAUERT A.M. and LEWIS P.R.: Biological specimen preparation for transmission electron - microscopy. Vol. 17. Pages 353-54, London: Portland Press, 1998.

27- ORTIZ G.G., BITZZER-QUINTERO O.K., ZARATE C.B., et al.: "Monosodium glutamate induced damage in liver and kidney: A morphological and biochemical approach". Biomedicine \& Pharmacotherapy, 6: 86-91, 2006.

28- INUWA H.M., AINA V.O., GABI B., OLA A. and JA'AFARU L.: "Determination of nephrotoxicity and hepatotoxicity of monosodium glutamate (MSG) consumption". British J. Pharmacology and Toxicology, 2 (3): 148-53, 2011.

29- KOLAWOLE O.T.: "Assessment of the effects of monosodium glutamate on some biochemical and hematological parameters in adult wistar rats". American J. Bioscience, 1 (1): 11-15, 2013.

30- JANBAZ K.H. and GILANI A.H.: Studies on preventive and curative effects of berberine on chemical-induced hepatotoxicity in rodents. Fitoterapia, 71 (1): 25-33, 2000.

31- EGBUONU A.C.C., EZEANYIKA L.U.S., EJIKEME P.M. and OBIDOA O.: "Histomorphologic alterations in the liver of male wistar rats treated with L-arginine glutamate and monosodium glutamate". Research J. Environmental Toxicology, 4 (4): 205-13, 2010.

32- ASHRY M.A., ABD ELLAH H.F. and GHETH E.M.M.: "The possible ameliorative effect of propolis in rat's liver treated with monosodium glutamate (MSG)". Nature and Science, 10 (12): 209-19, 2012.

33- DIAB A.E.A. and HAMZA R.Z.: "Monosodium glutamate induced hepatotoxicity and the possible mitigating effect of vitamin C and propolis". J. Advances in Medical and Pharmaceutical Sciences, 7 (4): 1-10, 2016.

34- MARIYAMMA T., SUJATHA K.S. and SISILAMMA G.: Protective effect of Piper longum (Linn.) on monosodium glutamate induced oxidative stress in rats. Indian Journal of Experimental Biology, 47 (3): 186-92, 2009.

35- EWEKA A.O. and OM'LNIABOHS F.A.E.: "Histochemical studies of the effects of Monosodium glutamate on the liver of wistar rats". Annals Med. Health Sci. Res., 1: 21-9, 2011.

36- BHATTACHARYA T., BHAKTA A. and GHOSH S.K.: "Long term effect of monosodium glutamate in liver of albino mice after neo-natal exposure". Nepal Medical College J., 13 (1): 11-6, 2011.

37- EGBUONU A.C.C., OBIDOA O., EZEOKONKWO C.A., EZEANYIKA, L.U.S. and EJIKEME P.M.: "Hepatotoxic effects of low dose oral administration of monosodium glutamate in male albino rats". Afr. J. Biotechnol., 8 (13): 3031-5, 2009. 


\section{السمية الكبدية المحدثة بجلوتامات آحادية الصوديوم والإجهاد التآكسلى دراسة باثوفسيولوجية كيميائية وإلكتروميكروسكوبية البودية}

$$
\text { مقدمة: الجلوتامات آحادية الصوديوم (MSG) هو محسن النكهة يستخدم على نطاق واسع. }
$$

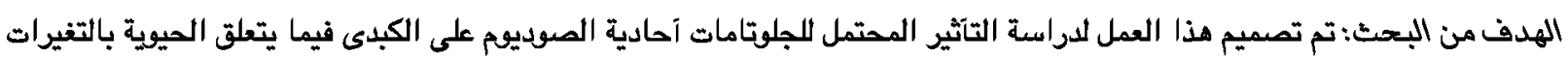

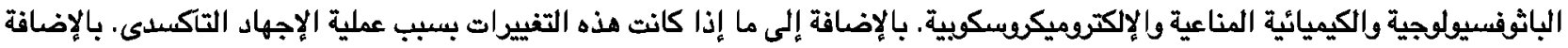

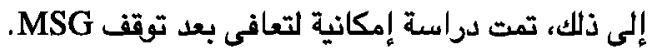

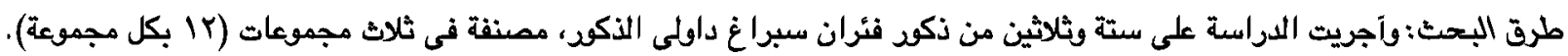

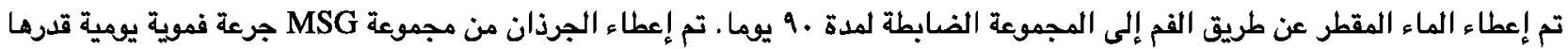

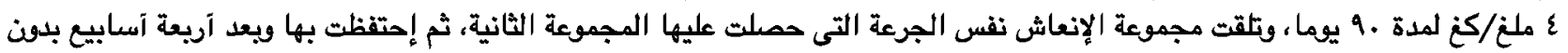

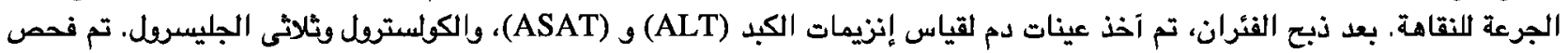

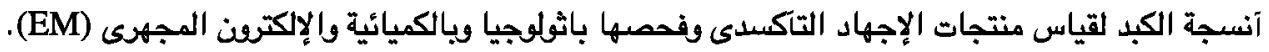

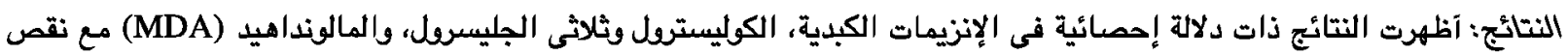

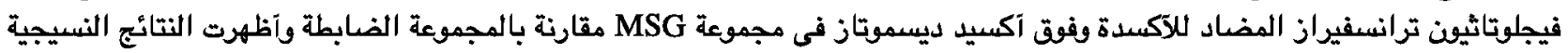

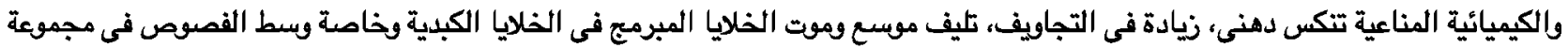

